Maurer School of Law: Indiana University

Digital Repository @ Maurer Law

1978

\title{
Reducing Legal Noise: A Comment on Clark, The Morphogenesis of Subchapter C: An Essay in Statutory Evolution and Reform
}

William D. Popkin

Indiana University Maurer School of Law, popkin@indiana.edu

Follow this and additional works at: https://www.repository.law.indiana.edu/facpub

Part of the Taxation-Federal Commons, and the Tax Law Commons

\section{Recommended Citation}

Popkin, William D., "Reducing Legal Noise: A Comment on Clark, The Morphogenesis of Subchapter C: An Essay in Statutory Evolution and Reform" (1978). Articles by Maurer Faculty. 1033.

https://www.repository.law.indiana.edu/facpub/1033

This Letter to the Editor is brought to you for free and open access by the Faculty Scholarship at Digital Repository@ Maurer Law. It has been accepted for inclusion in Articles by Maurer Faculty by an authorized administrator of Digital Repository @ Maurer Law. For more information, please contact rvaughan@indiana.edu. 


\title{
Correspondence
}

\author{
Reducing Legal Noise: A Comment on Clark, The Morpho- \\ genesis of Subchapter C: An Essay in Statutory \\ Evolution and Reform
}

To the Editors:

Professor Clark, in a recent essay, ${ }^{1}$ exposes the structural foundation of the corporate tax edifice, which lies hidden beneath its rococo exterior. ${ }^{2}$ He uses this foundation to explain the growth of existing law ${ }^{3}$ and the effects of selective changes in the existing structure. ${ }^{*} \mathrm{He}$ then presents a particular combination of changes as a promising reform package. ${ }^{5}$ The proposed reform is "legal" in the sense that its objective is simplification of the law to reduce the "legal noise" or, as economists put it, the transaction costs in the prevailing corporate tax culture. ${ }^{6}$ Although Professor Clark is worried about tax neutrality for different forms of doing business, ${ }^{7}$ his main concern is with simplification. ${ }^{8}$

I wish to raise some questions about how Professor Clark's promising reform package would reduce legal noise. Part I explains the details of the package and considers whether some of its provisions are in fact necessary to reduce legal noise. Part II then questions whether simplification would actually result from adoption of the package. Finally, Part III drops the requirement that the general tax culture not be altered and looks at another reform to see what effect it would have on legal noise.

\section{How Would Professor Clark's Reform Package}

Reduce Legal Noise?

Professor Clark's "corporate tax culture" consists of seven principles divided into three groups: the double tax set (principles one and two: the separate corporate tax and the tax on distributions to shareholders); the capital gains set (principles three, four, and five: taxing dispositions of property at capital gains rates, the presumption that corporate distributions are dividends, and the separation of corporations and shareholders

1. Clark, The Morphogenesis of Subchapter C: An Essay in Statutory Evolution and Reform, 87 YALE L.J. 90 (1977) [hereinafter cited by page number only].

2. Professor Clark prefers the baroque image, p. 97.

3. Pp. 96-135.

4. Pp. 135-52.

5. Pp. 153-61.

6. Pp. 135-37.

7. See, e.g., pp. 137, 155.

8. Pp. 135-37, 161, I6I n.241. 
such that shareholder dispositions are not affected by corporate tax attributes); and the nonrecognition set (principles six and seven: treating distributions and exchanges as nontaxable events when the shareholder's investment undergoes little or no change, and the nonrecognition of gain or loss to the corporation when it distributes property). ${ }^{9}$ The "promising" reform package, ${ }^{10}$ to which Professor Clark devotes the last major section of his essay, consists of three changes.11 First, the double tax set would be abolished by integrating the taxation of corporations and shareholders so that corporate income would be taxed at the shareholder's tax rate. Distributed income would be taxed only to shareholders. Undistributed income would be subject to a corporate withholding tax at the highest individual tax rate, but the tax would be credited against the shareholder's tax when the income was reported on the shareholder's return. Undistributed income could be allocated to the shareholders by the corporation. This allocated income would be reported by the shareholder in the year earned by the corporation; such income, reduced by the withholding tax, would be added to the shareholder's basis. Unallocated income would be reported by the shareholder when and if distributed in a later year. ${ }^{12}$ Second, preferential capital gains rates would be abolished, ${ }^{13}$ and, third, appreciation or depreciation in corporate property would be recognized when the property was distributed.14

Not all of these elements of the reform package are essential to reduce the legal noise with which Professor Glark is most concerned. Integration of the taxation of corporations and shareholders would clearly make the major contribution to reducing the decibel count. The incentive to disguise dividends (as salary or rent, for example) would be eliminated, because dividends would not be doubly taxed.15 The incentive to retain corporate income would be ended and with it the need for accumulated earnings and personal holding company taxes, because retained earnings would be taxed at the highest individual tax rate. ${ }^{16}$ Subchapter $\mathrm{S}$ election would be almost irrelevant, for corporate income would not be subjected to a greater burden than that on partnership income, with the exception that unallocated income would be taxed at the highest individual tax rate prior to distribution. ${ }^{17}$ The double taxation of corporate sales, dealt with in section 337, would no longer be a problem, because corporate in-

9. Pp. 96, 153. For more thorough discussions of the principles, sce pp. 97-104 (double tax set), 97-117 (capital gains set), 117-35 (nonrecognition set).

10. P. 94 .

11. Pp. 153-61.

12. This method of integrating the taxation of corporations and shareholders is similar to that proposed by the Canadian Carter Commission Report. P. 153; see pp. 153-55 (setting out integration scheme).

13. Pp. $153,155$.

14. Pp. $153,160 \cdot 61$.

15. Pp. 155-56. Note that Professor Clark's discussion assumes that the capital gains preference too has been eliminated, see p. 155; its absence, however, does not affect most of the projected results of the reform package.

16. P. 156 .

17. Pp. 155-56. 


\section{Correspondence}

come allocated to the shareholder would increase the shareholder's basis. ${ }^{18}$ Prevention of bailouts that convert dividends to capital gains would no longer be necessary, because the corporate withholding tax would have subjected corporate income to the highest possible tax rate. ${ }^{18}$

Integrating the taxation of corporations and shareholders would not, however, deal with another major source of complexity-the conversion of unrealized appreciation of ordinary-income property at the corporate level into capital gains at the shareholder level. Current law already deals with this problem through the collapsible corporation provisions, which convert the capital gain on the disposition of stock into ordinary income. ${ }^{20}$ Those provisions, however, are the source of a great deal of legal noise. One method suggested by Professor Clark as a way to eliminate this problem is to abolish preferential tax treatment for capital gains. ${ }^{21}$ It is not apparent, however, why Professor Clark makes this suggestion a necessary part of his promising reform package, ${ }^{22}$ since he also proposes to prevent the conversion of ordinary income into capital gains by recognizing gain when property is distributed by the corporation. ${ }^{23}$ Abolition of the capital gains preference is a sufficient but not a necessary method of eliminating the legal noise in the collapsible corporation provisions, a point Professor Clark seems to make earlier in his essay. ${ }^{24}$

18. Pp. 154-55.

19. P. 156. Professor Clark here refers to the partial elimination of "simple bailouts," by which he means devices for using the rule that dispositions of stock presumptively produce capital gains to avoid the ordinary income tax on corporate distributions (presumptively dividends), often through the medium of a liquidation or redemption. See p. 113 (defining "simple bailouts" as those not involving sixth or seventh principles), pp. 111-16 (describing various types of simple bailouts).

20. I.R.C. $\$ 341$.

21. P. 146 .

22. P. 155.

23. Pp. 160-61. The purchaser of stock who realized ordinary income on distribution of appreciated corporate property would increase his basis if the taxation of corporations and shareholders were integrated, pp. 154-55, thereby creating a loss at the shareholder level. If capital gains taxation were retained, however, this would be a capital loss, most of which could not offset ordinary income, I.R.C. $\$ 1211(3)$.

24. P. 152. Professor Clark makes one other point about his reform package that seems unnecessary. He alludes to a tax avoidance potential resulting from the computational disparity between corporate distributions, which are taxable without recovery of basis, and dispositions, which are taxable after first allowing for recovery of basis. P. 157. This disparity invites schemes for realizing gain at the shareholder level through transactions that qualify for disposition-type treatment and creates, in Professor Clark's view, the possibility of a "recovery of cost bailout," regardless of whether the property is a capital asset. P. 157 \& n.23I.

The supposed bailout technique can be illustrated using the figures in Professor Clark's cxample at p. 158 n.235. A corporation has two items of property, one with a cost of $\$ 10$, which has appreciated to $\$ 50$, and the other with a cost of $\$ 50$, which has retained its $\$ 50$ value. The shareholder's basis in the stock is $\$ 60$, which reflects the total cost of the two items of property. If the shareholder sells half his stock for $\$ 50$, the amount realized is reduced by half his cost, $\$ 30$, and he realizes a $\$ 20$ gain. This treatment of dispositions must be contrasted with a distribution of property by the corporation to understand the bailout potential. Although Professor Clark does not give an example of how a distribution would be taxed, he presumably would tax the value of the dis- 
One could argue that, even if the corporation must recognize gain when corporate property is distributed, preferential capital gains rates give the selling shareholder an improper advantage by allowing him to deflect to the purchaser the ordinary income represented by the gain in corporate property. Although the collapsible corporation rules have always been perceived as preventing conversion of ordinary income to capital gain, not as preventing assignment of income, ${ }^{25}$ a tax system that integrates the taxation of corporations and shareholders ought to be particularly sensitive to the assignment of ordinary income by one shareholder to another, especially since the purchaser may be tax-exempt or have operating losses to offset against corporate income attributable to shareholders. Accepting this as a real concern, however, requires only that the corporate veil be pierced to tax as ordinary income the shareholder's portion of the unrealized gain on the corporation's ordinary-income property, a technique employed by current law when partnership interests are sold, 26 and that rules be adopted to determine when a shareholder's activities convert corporate capital gains into shareholder ordinary income, analogous to those used for collapsible 27 and Subchapter $S^{28}$ corporations.

Of course, such rules are difficult enough to administer when business entities are owned by a few investors; they would be virtually unadministrable in the context of publicly owned businesses. It would be easier to

tribution to the shareholder without reduction for cost, because only then would distributions be taxed less favorably than dispositions.

The difficulty with this argument is that the distribution with which one must contrast the treatment of dispositions must, Iogically, be a distribution of the appreciated property itself, and there is no apparent reason why an integrated system of taxing corporations and shareholders should tax shareholders on the value of appreciated property upon distribution. It seems more reasonable to treat earnings, if any, as retained earnings and to treat the distribution of the appreciated property as an event in which the shareholder steps into the corporation's shoes by taking over the corporation's basis. Indeed, that is precisely the method of taxing distributions of partnership property. I.R.C. $\$ \S 731(a)(1), 732(a)(1)$. Because the distribution of appreciated property would not be taxed less favorably than a sale of stock, there should be no potential for a recovery of cost bailout.

Perhaps Professor Clark is concerned with the taxpayer's avoiding tax on the appreciated gain in the property, which cost $\$ 10$ and is now worth $\$ 50$, upon sale of his stock. It is true that, if the corporation sold all the property and distributed the gain, the shareholder would realize income of $\$ 40$. But the shareholder does not sell the property itself: he sells half the corporation, represented by half the stock. It is thus more accurate to compare the sale of stock to the sale of half of each item of property, rather than to the sale of all the appreciated property. If half of each item of corporate property were sold, the corporation would realize a $\$ 20$ gain $(\$ 25$ of income minus $\$ 5$ of basis for the appreciated item; plus $\$ 25$ of income minus $\$ 25$ of basis for the nonappreciated item); this is equal to the realized gain on the sale of half the stock. There is therefore no reason to view the recovery of cost on the sale of stock as a bailout scheme.

Underlying Professor Clark's comments may simply be a concern with the failure of existing law to tax unrealized appreciation; taxing unrealized gains, however, is a reform that goes well beyond modifying the corporate tax culture.

25. A selling shareholder can claim capital gains treatment if the corporation has elected to recognize gain on distribution of the property. I.R.C. $\$ 341(f)$.

26. Id. $\S 751$.

27. $I d . \$ 341(\mathrm{e})$.

28. Treas. Reg. $\$ 1.1375-1(d)$. 
eliminate the capital gains preference and be done with these complexities. But the capital gains preference, as Professor Clark notes, ${ }^{29}$ is an independent principle, not limited to the corporate context. Its elimination would alter the general tax culture as well as the corporate tax system in major ways, a tactic Professor Clark rejects in another setting. ${ }^{30}$ There is nothing wrong with effecting such sweeping changes in the general tax law to reduce legal noise. But once we admit to changes in the general tax culture as a technique for reducing legal noise in the corporate tax system, there is no reason to limit our concern to the capital gains preference-a point to which I will return below.

\section{What Legal Noise Would Be Reduced?}

My comments so far have accepted the specific simplification objectives posited by Professor Clark, which aim to eliminate planning and auditing complexities that concern a fairly small class of taxpayers. ${ }^{31}$ Most government officials would probably emphasize a different concept of simplification-the reduction of computation problems for large numbers of taxpayers. ${ }^{32}$ The paradigmatic reform to deal with this type of complexity is the standard deduction, ${ }^{33}$ which in effect leaves large numbers of taxpayers out of the general tax culture by eliminating the advantage of itemizing deductions. The problem raised by Professor Clark's reform package is that it may abandon the computational simplicity of the existing system to reduce tax planning and audit complexity.

The source of the problem is integrating the taxation of corporations and shareholders. Complete integration would pass through the attributes of income, deductions, and credits from the corporation to the shareholder, in a manner similar to the partnership ${ }^{34}$ and trust ${ }^{35}$ rules. "Pass-through" of corporate tax attributes is important for two reasons. First, preferentially taxed income must retain its preference in the hands of shareholders (that is, the preference must be passed through to shareholders) if the objective of reforming the corporate tax culture is limited to simplification and not expanded to encompass a general restructuring of the tax law. ${ }^{36}$ Sec-

29. P. 105.

30. P. 160 .

31. The main targets for simplification are the schemes adopted by closely held corporations to reduce taxes: disguising dividends as salary or rent; retaining earnings to avoid tax on dividends; avoiding double taxation on sale and liquidation of a business; bailing out dividends as capital gains; and converting unrealized ordinary income to realized capital gains. Pp. 155-61. The number of shareholders concerned with these schemes is small compared to that of shareholders of publicly held corporations.

32. See, e.g., Woodworth, Tax Simplification and the Tax Reform Act of 1969, 34 Law \& Contemp. Prob. 711 (1969).

33. The new term is "zero bracket amount," I.R.C. $\$ 63(\mathrm{~d})$.

34. Id. \$ 702; Treas. Reg. \$ 1.702-1.

35. I.R.C. $\$ \S 652(b), 662(b)$; Treas. Reg. $\$ \S 1.652(b)-2,1.662(b)$.

36. One proposal for integrating the taxation of corporations and shareholders considered eliminating or reducing tax preferences. Committee on Corporations of the Tax Section of the New York State Bar Ass'n, Report on the Integration of Corporate and Individual Income Taxes, 31 TAx LAw. 37, $42-45$ (1977) [hereinafter cited as Report on Integration of Taxes]. 
ond, avoidance of limitations on various tax preferences by using the corporate form of doing business must be prevented; otherwise, integration would introduce a bias in favor of corporations. Such limitations would be avoided if the attributes of corporate income, deductions, and credits were not passed through to shareholders. ${ }^{37}$

"Complete" integration, with mandatory pass-through of preferences and limitations, would require a radical change in the shareholder's obligation to compute his tax. One of the major simplifying provisions of existing law is its use of corporate earnings and profits to define dividends; this in effect homogenizes different types of income so that the shareholder need report only "dividend" income. By contrast, complete integration would insist that the shareholder identify the following types of income on his return: income subject to special tax rates, such as tax-exempt income or capital gains; special deductions, such as depletion and accelerated depreciation; and tax credits, such as the investment tax credit. The complexities of such reporting have led recent commentators on integration proposals to reject such a system, ${ }^{38}$ a position with which Professor Clark should agree, given his concern with the administrative problems of piercing the corporate veil. ${ }^{39}$

A modified form of integration would avoid many, though not all, of the reporting complexities but could be accomplished only if the problem of favoring the corporate form of doing business were disregarded, and the only objective were to pass through the advantages of tax preferences. Most tax advantages are passed through to shareholders simply by accepting the corporation's computation of income as the shareholder's income. Assume, for example, a corporation with $\$ 100$ of tax-exempt income, $\$ 100$ of income eligible for a $\$ 20$ depletion allowance, and a $\$ 20$ accelerated

37. See, e.g., I.R.C. $\$ \S 613$ (a) (ceiling on depletion equal to $50 \%$ of taxpayer's taxable income), 617(h) (specific dollar ceiling on current deduction of mining exploration expenditures), 46(a)(3) (dollar limit on investment credit).

The failure to pass through these items is inconsistent with the imputation of tax preference items to shareholders of Subchapter $S$ corporations for purposes of the minimum tax, id. $\$ 58(d)(1)$. Subchapter $S$ corporations also pass through to shareholders eligibility for the investment credit, $i d$. $\$ 48(\mathrm{e})$, and capital gains, $i d$. $\$ 1375(\mathrm{a})$.

38. 4 RePort of The Royal Commission on Taxation 676-77 (1966) (Canada); McClurc, Integration of the Personal and Corporate Income Taxes: The Missing Element in Recent Tax Reform Proposals, 88 Harv. L. Rev. 532 (1975). I have used the term "completc integration" to mean the fullest possible integration, which passes through to the shareholder all corporate income attributes. See pp. 1223-24 supra. McClure clearly rejects such a "partnership approach" on the ground of administrative infeasibility, though he considers it the "most desirable [conceptual] approach," see McClure, supra at 562-64. McClure uses the term "complete integration" to describe a number of integration methods in order to distinguish them from "partial" or "dividends-only" integration, see id. at 549-61, 581; he ultimately urges "complete integration" in a form similar to that proposed by the Canadian Royal Commission on Taxation (Carter Commission), see id. at 573 \& n.161, 581, which likewise disapproved the partnership method, see 4 REPORT OF THE ROYAL COMMISSION ON TAXATION, supra. Cf. Report on Integration of Taxes, supra note 36 , at 37-39, 63 (describing alternative forms of integration; noting that no industrialized country now uses "fully integrated" system; and concluding that such system appears infeasible).

39. P. 108-10. 


\section{Correspondence}

deduction for intangible drilling expenses. Corporate income is $\$ 60$. If we disregard any limitations on the shareholder's eligibility for tax advantages, $\$ 60$ would also be the shareholder's income. If, in addition, the $\$ 60$ had been invested in machinery eligible for a $10 \%$ investment credit, the corporate withholding $\operatorname{tax}$ at the highest individual tax rate would be $\$ 36$ $(70 \% \times \$ 60=\$ 42$, less a $\$ 6$ credit $)$. The shareholder would obtain the advantage of the investment credit simply by taking a withholding tax credit of \$42-the withholding tax without reduction for the investment credit. 40

But a modified form of integration such as that described above would not pass through the limitations on tax preferences, for the limitations operate only at the shareholder level. Such a system, then, would necessarily favor the corporate form of doing business. Nor could pass-through of the tax advantages for income taxed at special rates, such as capital gains, be accomplished without separate reporting of such items. And the use of the corporation's income to measure the shareholder's income would still mean that shareholder income remained tentative until an audit of the corporation's tax return had been completed. ${ }^{41}$

Perhaps we should be concerned with the problem of favoring the corporate form of doing business only when the owners of the corporation appear to have manipulated the tax system to achieve an advantage, that is, when the entity is owned by a few shareholders rather than by the general public. A mandatory pass-through of all corporate tax attributes would then be required only for owners of Subchapter $S$ type corporations, and the tax law would in effect recognize two corporate tax cultures. ${ }^{42} \mathrm{But}$ such a system would have the drawback of introducing considerable legal noise as taxpayers struggled to come within the most favorable corporate tax regime.

\section{A Consumption Tax: An Alternative Method of Reducing Legal Noise}

Since there is no easy way to simplify the corporate tax culture without modifying the general tax culture, such as by repealing the capital gains preference or allowing the ceilings on tax advantages to be circumvented, we should allow our imaginations to roam even farther than Professor Clark has suggested and consider what major changes in the general tax structure might radically simplify the corporate tax system. One such change is the adoption of a consumption tax: a tax on income minus savings.

40. Assume the individual's tax rate is 50\%. With a $\$ 6$ tax credit, his net tax should be $\$ 24(50 \% \times \$ 60=\$ 30$, minus $\$ 6)$. A corporate tax of $70 \%$ minus a $\$ 6$ credit results in a withholding tax payment of $\$ 36(70 \% \times \$ 60=\$ 42$, minus $\$ 6)$. The shareholder, however, would report a withholding tax payment of $\$ 42(70 \% \times \$ 60)$; this would result in a refund of $\$ 12(\$ 42$ minus $\$ 30)$. The $\$ 12$ refund reduces the $\$ 36$ corporate tax payment to a net tax of $\$ 24$.

41. One proposal would allocate audit adjustments to shareholders in the year of the adjustments. U.S. Treas. DeP'T, Blueprints for TAX Reform 74 (1977).

42. Cf. H. Gumpel, World Tax Series: Taxation in the Federal Republic of GerMaNY $\$ 12 / 2.1 a$, .lb, at 3019-25 (Harvard Univ. Int'l Program in Taxation 1969) (publicly and nonpublicly owned corporations taxed differently). 
Professor Andrews has already explained how a consumption tax ${ }^{43}$ can simplify the general tax system, but its advantages in simplifying the corporate tax culture should not be overlooked. The corporate tax would be abolished, for corporate income would be savings from the individual shareholder's perspective.44 Without a double tax on dividends, there would be no incentive to disguise dividends. Penalty taxes on retained earnings would be unnecessary, because there would be no bias against savings in the form of retained earnings. No Subchapter S elections would be necessary, because there would be no corporate tax to avoid. Bailouts would not be a problem if the capital gains preference were eliminated, a step that would reasonably follow once savings had received the benefit of a full deduction. And recovery of cost problems would not exist, for cost basis, which is previously taxed savings, would not exist. A consumption tax would carry its own potential for legal noise, however, because it would heighten the need for a tax on the enjoyment derived from wealth.45 And efforts to measure wealth periodically would require a major restructuring of tax administration, ${ }^{46}$ albeit one that many other countries have attempted. ${ }^{ \pm 7}$

\title{
Conclusion
}

Professor Clark's essay demonstrates the analytical power derived from understanding endogenous legal evolution. It is difficult, however, to contain a discussion of the corporate tax culture within "comparatively clear boundaries," 48 as my discussion of the capital gains preference should illustrate. ${ }^{49}$ When we begin to think seriously about reform to reduce legal noise, the linkages between the corporate tax subculture and the broader tax culture cannot be overlooked.

\author{
William D. Popkin \\ Professor of Law \\ Indiana University School of Law \\ (Bloomington)
}

43. Andrews, A Consumption-Type or Cash Flow Personal Income Tax, 87 Harv. L. REV. 1113, 1148-50 (1974).

44. The corporate tax might persist, however, on the theory that major conglomerations of power should be taxed. Cf. I.R.C. $\$ 4940$ (taxing investment income of private foundations).

45. Andrews, supra note 43 , at $1169-73$.

46. Id. at $1141-43$.

47. See C. Sandford, Taxing Personal Wealth 186-87 (1971).

48. P. 91 .

49. See pp. 1321-23 supra. See also note 24 supra (discussing taxation of unrealized appreciation). 


\section{Correspondence}

\section{Author's Reply:}

I was delighted to read Professor Popkin's illuminating observations ${ }^{1}$ about my recent article. ${ }^{2}$ His comments fall into three distinct categories, and I should like to respond to each.

\section{Capital Gains}

Professor Popkin states that it is not apparent why I urge abolition of the capital gains preference as a "necessary part" of my tentative reform package. ${ }^{3}$ His statement could mean only that in my article I did not show clearly how this would make a significant contribution to simplicity in the corporate tax culture, independently of the contributions made by the other elements of my package. I accept this criticism. My analysis of the implications of the package was fairly global, not oriented to tracing the exact contributions of each component.

Professor Popkin's statement might also mean that abolition of the capital gains preference would not in fact make a significant independent contribution to simplicity. This interpretation I reject. I do not think that Professor Popkin really disagrees, for he himself discusses two considerations that argue persuasively for abolition of the preference. First, he notes that the rate differential presents certain assignment-of-income problems. ${ }^{4}$ Initially, he says that this concern requires "only" certain veilpiercing adjustments, but, after referring to three analogically relevant patterns in existing law (in the partnership, Subchapter S, and collapsible corporation areas) and confessing that they generate a lot of legal noise, he admits that abolition of the capital gains preference may well be the preferable route for avoiding these complexities. ${ }^{5}$ Second, his discussion in Part II of his letter correctly points out the computational complexities that the distinction between capital gains and ordinary income, as well as the need to determine whether and how these characterizations should be passed through to shareholders, might create in an integrated tax system. ${ }^{\circ} \mathrm{My}$ article nowhere defines the simplicity objective to exclude these sorts of complexities, and I certainly would not want to rule them out of my concern. This second consideration, then, reinforces my recommendation that capital gains be abolished.

A third reason for thinking that abolition of the capital gains preference would itself promote simplicity was not made explicit in my article and is not addressed in Professor Popkin's comment. To make the point requires a running start. Professor Popkin's core intuition in Part I of his letter is twofold. He first notes that, given a complete integration scheme

1. Popkin, Correspondence, 87 YALE L.J. 1319 (1978) [hereinafter cited without cross reference as Popkin].

2. Clark, The Morphogenesis of Subchapter C: An Essay in Statutory Evolution and Reform, 87 YALE L.J. 90 (1977) [hereinafter cited by page number only].

3. Popkin at 1321 .

4. Id. at 1322 .

5. Id. at $1322-23$.

6. Id. at 1323-25. 
with appropriate stock-basis adjustments, the incentive to engage in what I call simple bailouts is virtually destroyed. ${ }^{\top}$ Second, given a complete integration scheme plus either abolition of the capital gains preference or reversal of the General Utilities principle,s collapsible bailouts are virtually destroyed. ${ }^{9}$ Professor Popkin thus concludes that "[a]bolition of the capital gains preference is a sufficient but not a necessary method of eliminating the legal noise in the collapsible corporation provisions."10

This twofold insight is basically correct, and a very good one. Nevertheless, the second point applies only to amounts of tax; it slights the importance of timing. Given an integration scheme and a reversal of General Utilitics, a shareholder ultimately would bear the same amount of tax, regardless of whether he cashed in on unrealized appreciation in his corporation's assets by a stock disposition or by a distribution. Nevertheless, the shareholder might reap a significant tax cleferral advantage by resorting to a transaction yielding disposition-type treatment. Adding abolition of the capital gains preference to the combination of integration plus reversal of the General Utilities principle, however, would preclude the shareholder from getting this deferral benefit. ${ }^{11}$ I doubt that I need

7. Popkin at $1320-21,1321$ n.19.

8. See pp. 130-35 (setting out General Utilities principle and its present ramifications); p. 152 (describing consequences of reversing General Utilities principle alone).

9. Nonrecognition bailouts pose more complicated problems, which Professor Popkin does not consider. See p. 1329 \& note 13 infra.

10. Popkin at 1321 .

11. Suppose that a complete integration scheme were adopted and that General Utilities were reversed. Shareholder $S$, who has marginal tax rates of $50 \%$ for ordinary income and $25 \%$ for capital gains, has formed corporation $X$. He originally contributed $\$ 200$ and received all 200 shares issued by the company. The purchased assets now have a fair market value of $\$ 300$. Compare the following tax patterns:

Pattern A: Asset Sale and Liquidation

$X$ sells the assets, which produce $\$ 100$ of ordinary income, retains the income, and allocates it to $S$. After the integration technique has been applied-X's payment of a $\$ 70$ withholding tax, the grossed-up constructive dividend to $S$, the credit to $S$, and the refund to him of $\$ 20$ (all described at pp. 154-55)-S will bear a $\$ 50$ tax burden; his shares will get a step-up in basis to $\$ 230$, and $X$ will possess $\$ 230$. If $S$ liquidates $X$, currently or in the future, then assuming nothing else changes, neither he nor $X$ will have gain or loss on the liquidation. The tax burden for this corporate asset sale-liquidation sequence is as follows:

Current year: $\$ 50$ to $S$

Future year: $\$ 0$ to $S$.

Pattern B: Stock Sale and Liquidation-Capital Gains Preference Retained

$S$ sells his stock for $\$ 300$ and pays a capital gains tax of $\$ 25$ on his $\$ 100$ gain. Several years later, the buyer, $P$, who has the same tax rates as $S$, liquidates the corporation. Because General Utilities has been reversed, the liquidating distribution of the appreciated property will produce $\$ 100$ of corporate-level ordinary income. Thus the liquidating distribution will have two parts: an actual distribution worth $\$ 100$, on which $P$ will pay a $\$ 50$ tax; and a nondividend distribution worth $\$ 200$, which, because of $P$ 's $\$ 300$ stock basis, will generate a $\$ 100$ capital loss. Assuming that $P$ has capital gains income to offset, this will produce a $\$ 25$ tax saving. Thus the pattern of net tax burdens is as follows:

Current year: $\$ 25$ to $S$

Future year: $\$ 25$ to $P$.

Pattern C: Stock Sale and Liquidation-Capital Gains Preference Abolished 
stress here that one should not think of deferral problems as involving "mere" deferral; the issue of timing is, after all, the source of countless conflicts in the tax culture. 12

A fourth reason for abolishing the capital gains preference is that doing so would simplify the tax system's response to nonrecognition bailouts, ${ }^{13}$ the one category of my three that Professor Popkin does not analyze. Moreover, there are reasons other than simplification for abolishing the capital gains preference; the primary one is that the preference makes no conceptual or policy sense in the first place. Though simplicity was the major concern of the final part of my article, it is hardly the only value that motivated the construction of the reform package.

Professor Popkin also seems to think it unnecessary for me to have bothered to worry about computational disparities between dispositions and distributions in an integrated tax scheme. ${ }^{14}$ The extended discussion

$S$ sells his stock for $\$ 3300$ and pays an ordinary income tax of $\$ 50$ on his $\$ 100$ gain. Several years later $P$, with the same tax rates, liquidates $X$. Again, the liquidating distribution will produce $\$ 100$ of corporate-level income $(\$ 300$, the value of the assets, minus $\$ 200$, the corporation's basis); $P$ will pay a $\$ 50$ tax on the dividend distribution and will have a $\$ 100$ loss on the nondividend distribution. Thus far the results are identical to those in Pattern B. But because the capital gains preference has been abolished in this example, $P$ 's $\$ 100$ loss will be an ordinary loss; he will thus enjoy a $\$ 50$ tax saving, which exactly offsets his $\$ 50$ tax on the corporate-level income. (The several distinct analytic steps in this example would actually occur simultaneously; one could collapse these steps instead of tracing the treatment of the corporate-level income, but the result would be the same.) The pattern of net tax burdens is as follows:

Current year: $\$ 50$ to $S$.

Future year: Ş0 to $P$.

Pattern C is like Pattern A. Pattern B produces the same amount of tax as the other two patterns, but half the tax is deferred for an indefinite period of time. Abolition of the capital gains preference precludes such deferral. In addition, the example assumes that $P$ 's tax rates are equal to $S$ 's only to eliminate assignment-of-income problems and thereby to emphasize that the point about deferral benefits is a distinct one.

12. For a succinct explanation of why this is true, see M. Chiretstein, Federal INCOME TAXATION 5 \& n.4 (1977).

13. For instance, the advantage of a Gregory-type bailout scheme, described at pp. 120-23, could virtually be destroyed by any reversal of the General Utilities principle that was so extreme as to apply to all spin-off distributions. But, assuming that businessmotivated spin-offs generally ought to be given nonrecognition treatment even when appreciated property is transferred to the spun-off company, this approach would throw the baby out with the bath water. Consequently, something like the complex conditions of present $\$ 355$ would still be needed. See pp. 122-23, 123 n.134. By contrast, abolishing the capital gains preference on the stock-sale component of the Gregory sequence would destroy the advantages of the scheme much more simply. A contemplation of the other nonrecognition bailouts, described at pp. 117-20, 123-30, will indicate that abolishing the capital gains preference would frequently take the fun (and profit) out of these devices in a simpler way than would either the present system's safeguard provisions or a reversal of General Utilities that realistically accommodated nonrecognition policies. The nonrecognition bailouts thus constitute a fourth independent reason for abolishing the capital gains preference.

14. See Popkin at 1321 n.24. More precisely, Professor Popkin disputes what he thinks to be my argument: that there would be potential for a "recovery of cost bailout." In the first place, the problem to which $I$ was alluding in my article was not described by me as a bailout, for it does not meet my definition of "bailout"-it does not involve conversion of ordinary income into capital gains. See pp. 95 n.13, 105. Moreover, Professor 
of this problem in my article suggested that the problem, which of course exists in the present system, is not feasibly solvable. ${ }^{15}$ It is easy to supply a numerical example to demonstrate that the disparity will continue to

Popkin goes on in the same footnote to set forth a numerical example of mine and explicitly supposes that I "presumably would tax the value of the distribution to the shareholder without reduction for cost, because only then would distributions be taxed less favorably than dispositions." He then proceeds to argue that it "seems more reasonable" to treat distributions of appreciated property as events in which the shareholder steps into the corporation's shoes by taking over its basis.

Since I am puzzled by the quoted language, I will here describe how a distribution of appreciated property would be treated under my package. Consider the example of mine that Professor Popkin restates and the following three courses of action by $S$.

(1) $S$ causes $X$ to distribute Asset B, the nonappreciated asset worth $\$ 50$, to himself. $X$ obviously has no gain or loss. Neither does $S$, for, even in the new system, distributions would have to come out of corporate income to be taxable to shareholders. The basis of $S$ 's shares is, however, reduced by $\$ 50$, as it would be under the present system.

(2) $S$ sells half his stock for $\$ 50$. He has gain, taxable as ordinary income, of $\$ 20$.

(3) $X$ distributes Asset $A$, the appreciated asset worth $\$ 50$ and with a corporate basis of $\$ 10$, to $S$. Because General Utilities has been reversed, $X$ recognizes income of $\$ 40$. Because the distribution of the property constitutes a distribution of this income, $s$, after application of the integration procedure, in effect bears a tax at his marginal rate on $\$ 40$. The basis of $S$ 's shares is reduced by $\$ 10$.

To me, it is a matter of regret that these three ways of producing what would be $\$ 50$ of benefit in a no-tax world would be taxed differently in the new system. $S$ would clearly prefer path (1) to path (2) and path (2) to path (3); there is a lack of tax neutrality. Furthermore, if $S$ had to choose path (2) for nontax reasons, he might try to make it look like path (1) by staging the sale as a redemption of half his stock by the corporation; he would then claim distribution-type treatment. In such a situation, the present system's problem of characterizing redemptions as sale-equivalent or distribution-equivalent would persist. These problems cannot be made to disappear, in my view, by asserting that it is "more accurate [metaphysically? poetically?] to compare the sale of stock to the sale of half of each item of property, rather than to the sale of all the appreciated property." Popkin at 1322 n.24.

Professor Popkin does make an excellent point when he suggests that distributions of property (other than money, of course) be given nonrecognition treatment, by analogy to the current treatment of partnership distributions. Id. (One might also draw an analogy to I.R.C. $\$ 333$.) To be sure, this would in one sense merely change the neutrality and characterization problems: paths (1) and (3) would then normally be preferred to path (2), but, when the corporation held property that had depreciated in value, the shareholders might stage distributions as redemptions and claim sale-type treatment in order to recognize a loss. But at least the neutrality problem seems an illusory one if we really accept the theory behind nonrecognition treatment: paths ( 1 ) and (3) are different from path (2) because they involve merely formal changes of ownership. Professor Popkin's suggestion, which in its largest aspect amounts to nonreversal of General Utilities plus expansion of the sixth (nonrecognition) principle, involves more ramifications, and more ambiguities needing resolution, than I can discuss here. It may indeed be the case that his suggestion would be an element in a tax-reform package superior to the one I have suggested.

In any event, unlike Professor Popkin, I persist in seeing a "recovery-of-cost-first" problem in my proposed system. Obviously $I$ do not think it so serious that $I$ would reject the reform package. Indeed, my position is, practically speaking, quite similar to Professor Popkin's: I would proceed despite the problem, whereas he believes it does not exist. I must point out, however, that "recovery of cost first" is not the only problematic aspect of the present computational disparity between distributions and dispositions that would persist in the new system. My article pointed out another as well, which is addressed in note 16 infra.

15. See pp. 157-60. 


\section{Correspondence}

be a problem, albeit, hopefully, a small one, even after the adoption of an integration scheme or of my complete package. ${ }^{16}$

\section{Concepts of Simplicity}

In dealing with the legal noise that reform might reduce, my article focused on the time and expense devoted to advising, planning, litigating, and teaching the law governing transactions that invoke the uncertain consequences of, or the inherent tensions among, the system's basic postulates. Professor Popkin summarizes these costs as "planning and audit complexities" and contrasts them with the computational complexities faced by all corporations and shareholders routinely filling out their tax returns. ${ }^{17}$ He is worried that an integration scheme would increase computational costs more than it would reduce the "planning and audit" costs. ${ }^{18}$ I feel much less worried. To put it graphically, if simplistically, he is worried about adding more lines to the reporting forms and keeping more records; I am worried about adding more pages to Bittker and Eustice's treatise and more items to the case law annotations in the loose-leaf services. Neither of us, however, has offered any cogent empirical evidence to sup. port our predilections. We are in the lawyer's familiar world of a priori discussion. I can adduce only a few debater's points here.

Though all corporations and shareholders have to prepare tax returns, it does not necessarily follow that the computational complexities of integration would be terribly expensive. For example, if all that were involved were the records and computations needed for carrying out the gross-up, credit, and stock basis adjustment features of the integration scheme, expenses need not be significant. The manipulations would be complex but could be routinized. It is not appropriate to refer to the Treasury Department's concern about the standard deduction and simplicity on individual tax returns as a paradigm;19 most affected taxpayers

16. The example in note 14 supra focused on appreciated corporate property. The same type of problem, traceable to the computational disparity, would exist with respect to corporate earnings. The key is to focus on a case in which earnings are retained but not allocated. Suppose that $S$, a shareholder with a marginal tax rate of $50 \%$, contributes $\$ 200$ to his corporation $X$ in return for its 200 shares. $X$ eventually earns $\$ 100$, but the income is not allocated. $X$ pays a withholding tax of $\$ 70$, it holds $\$ 30$ of net retained carnings, and $S$ 's stock basis of $\$ 200$ is not changed. Several years later, $S$ wants to cash in on the value of the retained earnings.

If $\mathrm{X}$ declares a dividend of $\$ 30$, the dividend is grossed-up, a $\$ 70$ credit is given, and $S$ receives a $\$ 20$ refund. There is no stock basis adjustment. See pp. 154-55 (explaining computations under integration technique). If, instead, $S$ sells enough stock to yield $\$ 30$ of sales proceeds-i.e., 26.08 shares: the desired income of $\$ 30$, divided by $\$ 230$ (the value of the company)-he will realize a taxable gain of $\$ 30$ minus $\$ 26.08$, or $\$ 3.92$, and will pay a tax of $\$ 1.96$. Thus the new system would contain a bias, in this hopefully infrequent situation, in favor of distribution-type treatment over disposition-type treatment. My article clearly acknowledged this, and noted that at least there would be no policy reason to require the Service to try to prevent taxpayers from casting transactions as distributions. P. 156.

17. Popkin at 1323 .

18. Id. at 1323-25.

19. Id. at 1323 . 
would undoubtedly have an accountant already assisting the preparation of their returns, and most accountants would not be fazed by the computations. A key fact is that taxpayers would not have to understand the integration procedure: the tax forms could and surely would present an algorithm for taking the preparer through the computation, step by step.

Existing law and forms suggest many analogies. For example, the provisions for income averaging 20 are, linguistically, fairly complex, and many taxpayers who use them may only dimly understand their basic purpose and may not understand their particular strategy at all. The form for income averaging is also complicated but so methodical and explicit that it requires only obedience, not thought, to complete it..21 Thus, although the statutory averaging provisions are indeed complex in a linguistic sense, they do not generate transaction costs in the way that, say, the phrase "reasonable needs of the business" does in the accumulated earnings tax provisions. ${ }^{22}$ When the averaging provisions do generate transaction costs, it is probably because of ambiguities in the key terms of the statute, not because of linguistic complexity or the complexity of the calculations required. Ambiguity and tensions among basic principles are the real sources of expensive complexity, that is, of "legal noise." 23

On the other side of the pair, the planning and litigating costs of the corporate tax culture that I focused on in my article can be extremely expensive. Legal advice to aid the planning of a transaction invoking ambiguities or conflicting principles can easily cost thousands of dollars; litigation expenses in a single case can equally easily involve tens or hundreds of thousands of dollars. And, though litigation may affect a small proportion of corporations and shareholders, legal planning is quite frequent in connection with stock redemptions (as, for example, in close corporations after the death of a major shareholder), liquidations, and sales of a business.

To be sure, Professor Popkin has in mind computational complexities far more subtle than those necessarily inherent in a full integration scheme. Many problems would arise from the desire to "pass through" preferences and to prevent the circumvention of limitations on preferences. As Professor Popkin recognizes, one source of trouble in this context is the capital gains preference, which I would abolish. ${ }^{24}$ I would also abolish many of the other preferences, for reasons unrelated to improvements in the corporate tax culture. Furthermore, many of the "complexities" that one would face when drafting an integration scheme into a concrete statute, such as those presented by the tax preference provisions, are in the first instance merely questions that the legislator must answer in one way or another, to the sacrifice of some current policy concerns. As a recent and rather detailed analysis by Professor Alvin Warren shows, ${ }^{25}$ how the questions are answered

20. I.R.C. $\$ \S 1301-1305$.

2I. Thought is generally more time-consuming than obedience.

22. See pp. 103-04.

23. This is a key point of my article, see, e.g., pp. 116-17.

24. See p. 1327 \& note 6 supra.

25. A. Warren, Integration of the Individual and Corporate Income Taxes (unpublished paper prepared for ALI-ABA Committee on Continuing Professional Education, Conference on Federal Income Tax Simplification, undated) (on file with Yale Law Journal). 
may have a significant impact on the level of reporting and computational complexity. Nevertheless, I must admit that Professor Popkin has made a good case that, if we want to retain some tax preferences and would be worried by circumventions of limitations on them, we have to make an unavoidable trade-off between reporting and computational complexities (which would arise from "passing through") and biases in favor of the corporate form (which would arise from not "passing through"). In any event, I would not, as Professor Popkin suggests I would, ${ }^{26}$ impose on reform proposals any general prohibition against changing the general income tax culture. I simply refrain from trying to do everything in one article.

I would add one comment about different types of simplicity and the differing roles they play in cultural explanations and reform analyses. In exploring the evolution of a legal culture, all types of simplicity or complexity are of interest. In the reform area, however, what counts is expensive complexity, which $\mathrm{I}$ tried to capture with the term "legal noise." In my view, it is proper for reformers not to be anxious to achieve linguistic and calculational simplicity per se, particularly in the corporate area (or, for that matter, wherever the advice of accountants is presumably already available). The bulk and intricacy of the Code and regulations should not worry us very much. If every Code section were ten pages long, filled with lists of conditions and qualifications, but generated no uncertainty of application and no litigation, the world would be a far better place than it is now. What are important are fundamental ambiguities and conflicts, which stem from deep-level theoretical disharmonies.

\section{A Discourse on Method}

Professor Popkin's most interesting point is that switching from an income tax to a consumption tax might effectively simplify the corporate tax culture. ${ }^{27}$ Perhaps so, perhaps not. I would rather have a more complete argument before I cease to worry about hidden complexities not now apparent. One of the major themes of my article, as its conclusion stressed, is the importance of method in the analysis of reforms-in particular, the importance of an axiomatic method. I would therefore suggest the following experiment, to be carried out by some interested tax analyst. ${ }^{28}$

Formulate a list of the basic principles or axioms of a consumption tax system, especially as they would apply to corporations and shareholders. Preferably, the formulation would be cast in statutory form. Then present the imaginary code to experienced tax lawyers and accountants and perhaps to a group of intelligent laymen. Assign them roles: some as various sorts of taxpayers, some as Internal Revenue officials, some as judges, and

26. Popkin at 1319,1325 .

27. Id. at 1325-26. But cf. id. at 1326 (consumption tax might introduce new sources of legal noise).

28. A note to the world: I am willing to receive a grant for this experiment; I'll gladly split it with Professor Popkin. 
some as Congressmen. Ask a pair ${ }^{29}$ of taxpayers to begin the game by devising a plan to reduce taxes. A pair of Internal Revenue officials next has a chance to argue against it and to write a prospectively applicable regulation to try to bar other taxpayers from a similar move. A pair of judges then decides how the conflict should be resolved, and the winner gets real money (supplied by the experimenters), though not, of course, in real-life proportions. A pair of Congressmen then has a chance, though not an obligation, to write a new statute, but not one that changes the system's basic postulates. Play is continued for many hours. A simulation technique of this sort might be a good way to predict the evolution of a consumption tax system.

Professor Popkin's suggestion that we let our imaginations roam beyond the limits explored in my article ${ }^{30}$ raises another question, a more general one than whether his proposed consumption tax would in fact simplify the corporate tax culture: what should determine, in any given inquiry into tax policy issues, the limits within which we roam? Obviously, differences in degrees of "fundamentalness" can be very great. One could easily roam beyond even Professor Popkin's suggestion: if we consider the consumption tax and simplicity, why not consider a value-added tax, or a head tax, and so forth? Why not consider the propriety of having any tax system at all? Why not consider the ultimate assumptions of the discussion, assumptions that realistically must be justified, if at all, in a philosophy of the state and of human nature, or in metaphysics and epistemology?

Policy analysis suffers from a perennial need to choose between two conflicting approaches. It can try to take account of all the obviously relevant variables and all the obviously relevant alternative solutions to problems. In this way, its general descriptions of relationships will be more realistic, and its conclusion may embody a better and more novel overall solution. Or it can exercise self-restraint, by self-consciously stipulating that some variables are constant and ruling out certain alternatives in advance, and then proceed to draw out the implications of its self-created model to the fullest possible extent. The advantage of this second tack is that (within the model, of course) one may discover or formulate interesting and perhaps not previously apparent relationships and reach conclusions accordingly. Like the physicist assuming friction to be zero in order to be able to conduct a thought experiment, or the economic analyst stipulating counterfactual conditions or fixed values of variables that he knows vary in the real world, the procedure enables systematic analysis. This approach is to be favored, I suggest, especially since the restrictive conditions can always be lifted in a later analytic inquiry. The

29. Groups are generally better at problem-solving tasks (as opposed to constructive or synthesizing activities) than is a series of individuals working alone. See, e.g., $\mathrm{P}$. Blau \& W. Scott, Formal Organizations 117 (1962) (discussing empirical studies). Thus it would be extremely important that players in my experiment work as teams, just as real-life taxpayers and their lawyers and accountants do. Otherwise, the generation of tax-reduction schemes might be discouragingly slow.

30. Popkin at 1325 . 


\section{Correspondence}

right time for me to ask about a consumption tax as an alternative to the income tax is precisely now, after Morphogenesis has appeared and many comments on it received.

I am concerned about assuming that if one restrictive condition of analysis is lifted, others should be lifted simultaneously. Professor Popkin remarks that "once we admit to changes in the general tax culture as a technique for reducing legal noise in the corporate tax system, there is no need to limit our concern to the capital gains preference." 31 There seems to me to be a very big difference between a proposal to abolish the capital gains preference in the income tax culture and a proposal to establish a consumption tax culture. For one thing, the former seems much more feasible, politically, ${ }^{32}$ and is therefore a more natural variable to consider changing in a first inquiry. More important, I feel reasonably confident, even without going through a systematic analysis, that abolishing the capital gains preference would also simplify the general income tax culture; the effect there would be consistent with my goals in the corporate tax area. Establishing a consumption tax would, as Professor Popkin himself points out, create various complexities and possibilities for legal noise. ${ }^{33}$ Without conducting an axiomatic analysis, I cannot be sure of the net ef. fect; I therefore view the change as a subject for separate, later analysis. Everything in its own time.

Robert C. Clark

Visiting Professor of Law

Harvard University

31. Id. at 1323 .

32. Before 1921, the preference did not exist in the income tax culture; its form has changed radically since then; and last year there was a serious though unsuccessful effort by the Administration to abolish it. See pp. 104-05, $104 \mathrm{n} .61$ (summarizing history of capital gains preference and citing sources).

33. Popkin at 1326 . 